\title{
Association of RS 7903146 (C/T) Single Nucleotide Polymorphism at Transcription Factor 7 Like 2 Gene with Type 2 Diabetes Mellitus
}

\author{
Hassnaa M. Nassar M.D. \\ Department of Clinical Pathology, Suez Canal University Faculty of Medicine, Ismailia Egypt
}

\begin{abstract}
Approximately 462 million people suffer from type 2 diabetes mellitus (T2DM) worldwide, and its prevalence is projected to increase to 7079 individuals per 100,000 by 2030 . The rapid increase in the prevalence of this disease is likely a result of multiple environmental factors as increased food intake and decreased physical activity in genetically predisposed individuals. Patients with T2DM are vulnerable to developing secondary complications like retinopathy, and nephropathy. For that reason, great effort has been made to identify genes associated with T2DM. Many loci were found to be associated with T2DM risk in various populations and ethnic groups as the transcription factor 7-like-2 gene (TCF7L2) gene (rs7903146) [C/T] polymorphism locus on chromosome 10q. The TCF7L2 (rs7903146) (C/T) contributes to the disease through the Wnt/ $\beta$-catenin signaling pathway affecting pancreatic islet development, expression of several genes involved in insulin granules exocytosis, and the incretin glucagon-like peptide 1 (GLP-1) gene.
\end{abstract}

Keywords: Wnt signaling pathway, genetics of diabetes mellitus, complication of diabetes mellitus.

\section{Introduction}

Type 2 diabetes mellitus (T2DM) represents a significant worldwide burden due to the increase in its incidence over the last decades and also due to the significant rate of its morbidity and mortality ${ }^{(1)}$. T2DM (formerly noninsulin-dependent diabetes mellitus (NIDDM) or adult-onset diabetes) is a metabolic disorder that is characterized by impaired insulin secre- tion; insulin resistance in muscle, liver, and adipocytes; and abnormalities in splanchnic glucose uptake ${ }^{(2)}$. Environmental and lifestyle changes are believed to play a role in the occurrence of T2DM, but the inherent susceptibility to the disease is widely attributed to complex genetic factors. There is evidence that genetic susceptibility to the disease is due to many genes, and genome-wide association studies (GWAS) have thus identified more than 
50 loci associated with T2DM risk(3). Single nucleotide polymorphisms (SNP) at the transcription factor 7 -like 2 gene (TCF $7 \mathrm{~L} 2$ ) locus on chromosome 10q25.3 have been found to be associated with T2DM risk in various populations and ethnic groups ${ }^{(4)}$. TCF7L2 gene encodes high-mobility box containing the transcription factor TCF7L2 protein, involved in the Wnt signaling pathway, which seems to be critical to pancreatic islet development and adipogenesis(5). TCF7L2 forms heterodimers with betacatenin to induce the expression of various genes, including the gene encoding the insulinotropic hormone glucagon-like peptide 1 , and the insulin gene ${ }^{(6)}$. Although the mechanisms underlying the association of TCF7L2 polymorphisms and alterations in glucose homeostasis are not clear, it was suggested that this transcription factor primarily affects insulin secretion, beta cell function and insulin sensitivity $(7)$. An intronic SNP at this locus, reference SNP (rs) rs7903146 (C/T), was found to be associated with T2DM risk in different ethnic groups, in studies done on European populations as England $^{(8)}$, Finland ${ }^{(9)}$ and Sweden ${ }^{(10)}$ and in nonEuropean populations as Indians( ${ }^{(11)}$ Han Chinese $^{(12)}$ and Persian ${ }^{(13)}$. It was found to be also associated with T2DM in Arabian populations as in Moroccan ${ }^{(14)}$, Pakistani ${ }^{(15)}$, Tunisian(16), and Palestinian ${ }^{(17)}$. However, lack of association was reported in United Arab Emirati ${ }^{(18)}$, Saudi Arabian ${ }^{(19)}$ and Egyptian ${ }^{(6,20)}$ populations.

\section{Diabetes Mellitus}

Diabetes mellitus (DM) is a group of metabolic diseases characterized by hyperglycemia resulting from defects in insulin secretion, insulin action, or both. The chronic hyperglycemia of diabetes is associated with long-term damage, dysfunction, and failure of different organs, especially eyes, kidneys, nerves, heart, and blood vessels ${ }^{(21)}$. According to the International Diabetes Federation (IDF), Approximately 463 million adults (20-79 years) were living with diabetes in 2019. DM is expected to rise to 700 million by $2045^{(22)}$. Marked hyperglycemia causes polyuria, polydipsia, weight loss, sometimes polyphagia, and blurred vision. Severe uncontrolled diabetes causes acute, life-threatening consequences as ketoacidosis or the non ketotic hyperosmolar syndrome ${ }^{(23)}$. Chronic complications can be divided into vascular and nonvascular complications. The vascular complications of T2DM are further subdivided into microvascular (e.g. retinopathy, neuropathy, and nephropathy) and macrovascular complications (e.g. coronary heart disease, peripheral arterial disease, and cerebrovascular disease) and non-vascular complications include problems such as gastroparesis, infections, skin changes, and hearing loss with longstanding diabetes ${ }^{(24)}$.

\section{Classification of Diabetes}

Diabetes can be classified into the following general categories: 1-Type 1 diabetes (due to autoimmune $\beta$-cell destruction, usually leading to absolute insulin deficiency), 2- Type 2 diabetes (due to a progressive loss of adequate $\beta$-cell insulin secretion frequently on the background of insulin resistance), 3-Gestational diabetes mellitus (diabetes diagnosed in the second or third trimester of pregnancy that was not clearly overt diabetes prior to gestation), 4- Specific types of diabetes due to other causes, e.g., monogenic diabetes syndromes (such as neonatal diabetes and maturity-onset diabetes of the young), diseases of the exocrine pancreas (such as cystic fibrosis and pancreatitis), and drug- or chemical-induced diabetes (such as with glucocorticoid use, in the treatment of HIV/AIDS, or after organ transplantation ${ }^{(25)}$. 


\section{Type 2 Diabetes Mellitus (T2DM)}

It ranges from predominantly insulin resistance with relative insulin deficiency to predominantly an insulin secretory defect with insulin resistance ${ }^{(26)}$. The risk of developing this form of diabetes increases with age, obesity, and lack of physical activity, women with prior gestational diabetes mellitus (GDM) and individuals with hypertension or dyslipidemia, and its frequency varies in different racial/ethnic subgroups ${ }^{(27)}$. Genetic elements are also involved in its pathogenesis ${ }^{(28)}$.

\section{Genetics of Type 2 DM}

It has been described as a "geneticist's nightmare"(29). The lifetime risk of developing $T_{2} D M$ is $40 \%$ for individuals who have one parent with T2DM and $70 \%$ if both parents are affected. In addition, the concordance rate of T2DM in monozygotic twins is about $70 \%$ whereas the concordance in dizygotic twins is $20 \%-30 \%(30)$. Genome Wide Association Study (GWAS) has identified 143 common risk variants associated with $T_{2} \mathrm{DM}^{(31)}$. Some of the GWAS genes associated with T2DM or impaired pancreatic islet function ${ }^{(32)}$. A point mutation may or may not change the function of a gene or its expression. The variant may influence a phenotype through different mechanisms, e.g. via affecting the promoter and enhancer activity, mRNA stability and alternative splicing, or protein functions. These are also reasons why certain SNPs predispose an individual to a common disease ${ }^{(33)}$. Several chromosomal regions, most notably chromosomes 2p, 2q, 7, 13, and 18 have been identified as regions likely to harbor T2DM susceptibility genes(34). Also, a few common variants in specific genes appear to be associated with T2DM across several studies. These include Transcription Factor 7-Like 2 (TCF7L2), Guanine nucleotidebinding protein subunit beta 3 (GNB3), Norepinephrine Transporter (NET), Potas- sium Channel gene (KCNJ11), and Glucocorticoid receptor (GRL) genes ${ }^{(35)}$.

\section{Transcription factor 7-like 2 (TCF7L2)}

TCF7 was originally isolated as a lymphoid transcription factor(36). cDNAs (core deoxynucleotides) for TCF7L1 and TCF7L2 were isolated, which were called TCF3 and $\mathrm{TCF} 4$, respectively(37). Because the high mobility group (HMG) boxes of the TCF7L1, TCF7L2, and TCF7 sequences show striking similarity, it was suggested that they represent a subfamily of TCF7-like HMG box-containing transcription factors ${ }^{(38)}$. The genomic structure of the human TCF7L2 gene was presented and mapped to chromosome 10q25.2-q25.3(39). It was found that the TCF7L2 gene contain 17 exons, including 5 alternative exons ${ }^{(40)}$. The TCF7L2 gene produces a transcription factor protein that is involved in the Wnt signaling pathway(41). Figure (1) presents the overall structure of the human TCF7L2 gene, the positions of the seven SNPs (rs7903146), (rs12255372), (rs7901695), (rs7895340), (rs11962055), (rs290487) and (rs11196218). They are mainly localized within the two large intronic regions surrounding exon $5^{(5,42)}$.

Allelic Variants

1.TCF7L2 (rs7903146)

A strong linkage was found between rs7903146, and a microsatellite marker in intron 3, DG10S478, and type 2 diabetes mellitus in study done on Icelandic population(43). He suggested that rs7903146 (T) allele is probably the best marker to evaluate the effect of this gene on T2DM risk(43). According to a meta-analysis study, rs7903146 was significantly associated with T2DM in Caucasian, East Asian, South Asian and other ethnicities ${ }^{(44,45)}$.

2. TCF7L2 (rs11962055)

An association was found between T2DM and the risk $C$ allele of rs11962055 ${ }^{(46)}$. 


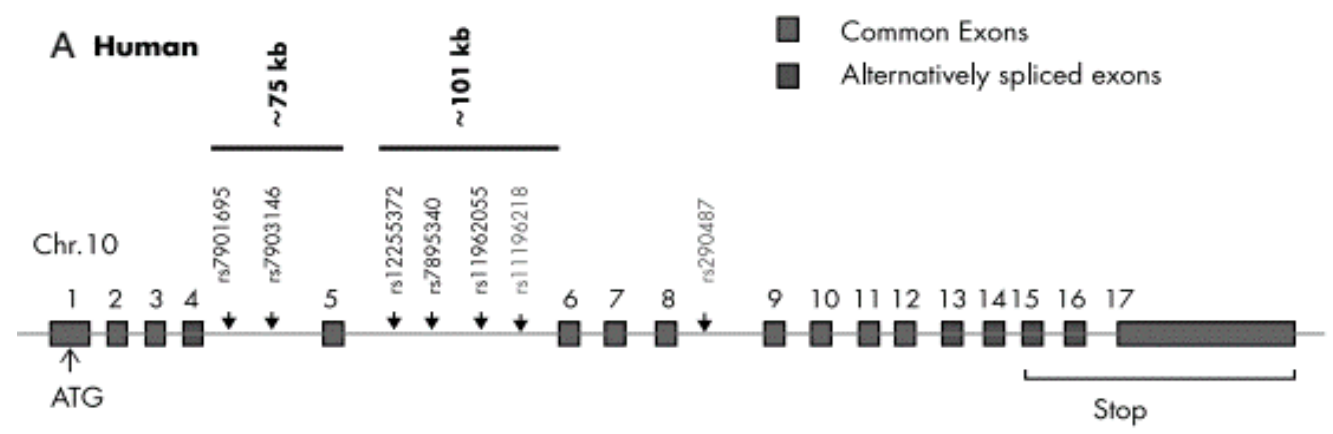

Figure 1: Diagrams show the structures of the human TCF7L2 gene (on chromosome 10)(5)

TCF7L2 is a member of the Wnt signaling pathway.

The Wnt signaling exerts many important physiological and pathophysiological functions in different cell lineages and organs, including organogenesis and the development and progression of tumors(47). Wnt was renamed according to the int1/Wingless (Wg) gene in Drosophila (48). Wnt signaling pathway was known from studies on colon cancer and embryonic development in Drosophila, Xenopus, and other organisms (49). The key effector of the canonical Wnt signaling pathway is the bipartite transcription factor $\beta$-catenin ( $\beta$-cat/TCF), formed by the heterodimerization of $\beta$-catenin ( $\beta$-cat) with one of the four TCF/LEF (lymphoid enhancer binding factor-1) factors (TCF1, LEF-1, TCF3 , and $\mathrm{TCF}-4)^{(40)}$. The concentration of $\beta$ cat in cytosol in a resting cell is controlled by the degradation process mediated by proteasome through the actions of adenomatous polyposis coli (APC) (encoded by the adenomatous polyposis coli gene), axin/conductin, the serine/threonine kinases glycogen synthase kinase-3 (GSK-3), and casein kinase $1 a^{(50)}$ (Figure 2). Wnt glycoproteins are a large family of cysteine-rich glycoprotein ligands secreted by undifferentiated or inflammatory cells and adipocytes(51). Wnt glycoproteins exert their effect as ligands via the seventransmembrane domain frizzled receptors
(Fz) and the LRP5/6 (low-density lipoprotein receptor-related proteins 5 and 6) coreceptors ${ }^{(52)}$ (Figure 2). After receptor binding, Wnt signals are transmitted by an association between the Wnt receptors and Dishevelled (Dvl), an event that triggers the disruption of the complex that contains adenomatous polyposis coli, axin, GSK-3, and $\beta$-cat, thus preventing the phosphorylation-dependent degradation of $\beta$-cat ${ }^{(53)}$. B -cat then enters the nucleus to form the $\beta$-cat/TCF complex and the activation of $\beta$-cat/ TCF (or Wnt) downstream target genes( ${ }^{(54)}$. CSK-3 is an important negative modulator of the Wnt signaling pathway. Lithium and other inhibitors of GSK-3 have been shown to mimic the function of the Wnt ligands in stimulating the expression of Wnt downstream target genes(55). In the absence of Wnt signaling, these HMG box TCF proteins function in the nucleus as transcriptional repressors of the Wnt target genes. The Wnt pathway is involved in regulating development and proliferation of $\beta$ cell and thereby pancreatic islet cell mass. Loss of $\beta$-catenin signaling leads to pancreatic hypoplasia(56) (Figure 2).

Expression and function of TCF7L2

TCF7L2 in intestinal endocrine L cells (Fig. 3): the expression of the proglucagon gene (gcg) leads to the production of the incretin hormone GLP-1 58 . 


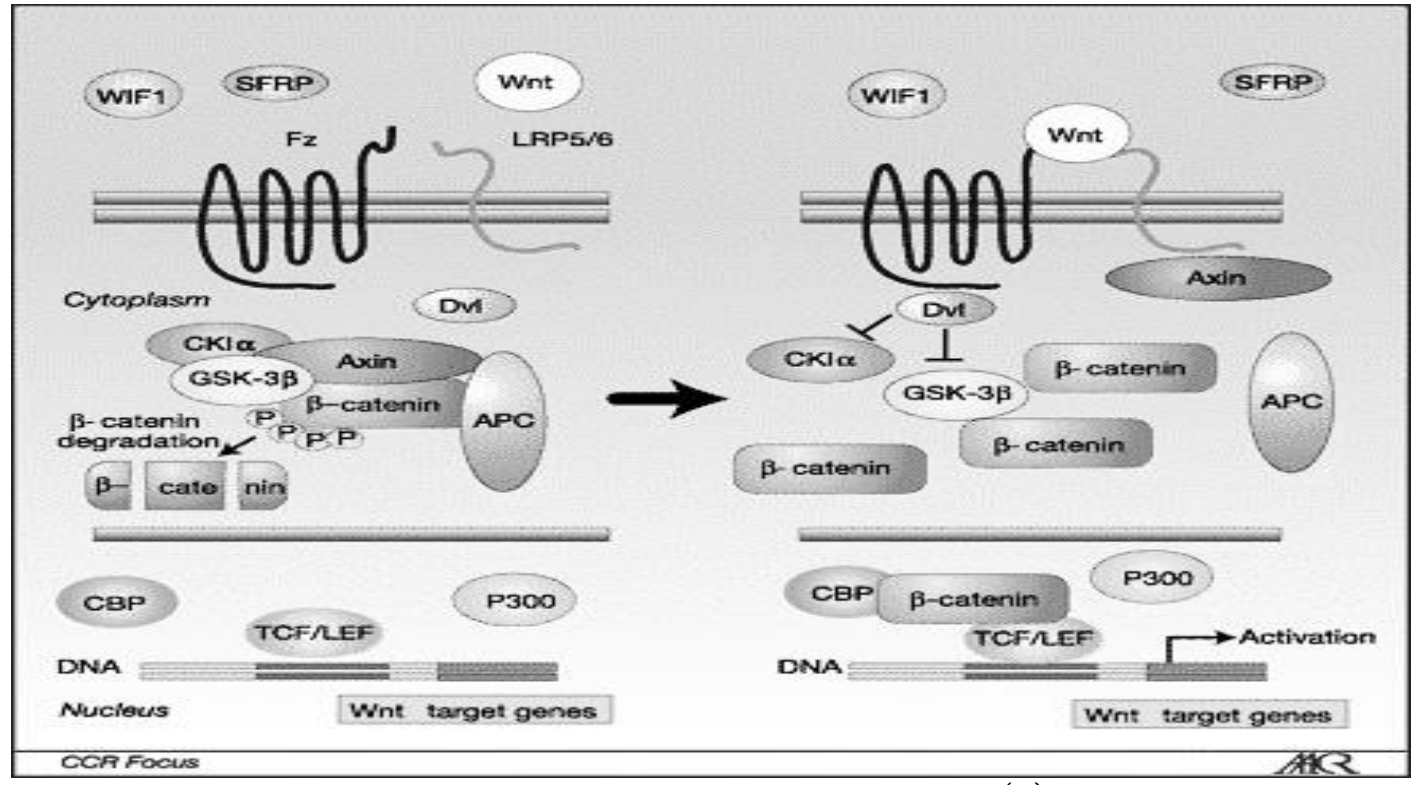

Figure 2: Canonical Wnt Signaling Pathway(57)

On the left: In the absence of Wnt: Protein complex formed by axin, APC, GSK- $3 \beta$, and CK1 $\alpha$ (named $\beta$-catenin destruction complex) binds to $\beta$-catenin, resulting in the degradation of $\beta$ catenin by $26 \mathrm{~S}$ proteasome system. On the right: in the presence of Wnt: Wnt binds to the receptor Fz nd co-receptor LRP5/6, these receptors mediate signals into cells and inhibit the function of $\beta$-catenin destruction complex. The accumulated $\beta$-catenin is translocated to nucleus to activates the transcription of target genes together with transcription factors (TCF/LEF). CK1a, casein kinase $1 \alpha$; sSFRP, secreted Frizzled-related proteins ${ }^{(57)}$.

It was found that both lithium (which mimics the function of the Wnt ligands) and the constitutively active $\beta$-cat stimulated the activity of the proglucagon gene promoter, so it increases endogenous proglucagon mRNA expression and GLP-1 production(59). TCF7L2 is abundantly expressed in both cultured intestinal GLP-1 producing cell lines and intestinal epithelia of adult mice. Furthermore, dominantnegative TCF7L2 intestinal endocrine cell line showed attenuated both basal and lithium-stimulated proglucagon mRNA expression $^{(60)}$. It was found that the stimulatory effect of lithium on gcg expression occurred in intestinal endocrine $L$ cells, but not in pancreatic $\alpha_{\text {-cells }}{ }^{(61)}$. Interest ingly, gip mRNA expression was also shown to be stimulated by the Wnt signaling cascade. It was demonstrated that lithium or $\mathrm{Wnt} / \mathrm{\beta}$-cat signaling enhances
GIP production by enteroendocrine cells through a conserved TCF binding site within the proximal region of the gip promoter(59).

TCF7L2 and pancreatic $B$ cells (Figure 3 )

TCF7L2 has a binding site in the promoter of the pre-proinsulin gene. Also, TCF7L2 influences both glucose- and incretinstimulated insulin secretions. Moreover, TCF7L2 plays a role in $\beta$ cell apoptosis, exocytosis (calcium handling) and islet cell morphology ${ }^{(62)}$. TCF7L2 silencing impairs glucose- and incretin- potentiated insulin secretion. Silencing TCF7L2 did not alter the insulin content, but reduce preproinsulin expression ${ }^{(63)}$. Decreased TCF7L2 protein expression in diabetic mice and T2DM patients is associated with reduced pancreatic islet GLP-1 and GIP receptor expression, which contribute to 
impaired $\beta$ cell function ${ }^{(64)}$. Exocytosis is a key step in secretion of insulin. TCF7L2 silencing in primary mouse islets, leads to defective insulin vesicle movement, vesicle fusion, glucose-stimulated ATP/ADP increment and calcium influx. But readily releasable insulin vesicle number was not affected by TCF7L2 silencing. Over expression of TCF7L2 was found to have a slight inhibitory effect on glucose stimulated calcium influx ${ }^{(65)}$. TCF7L2 has also been shown to mediate GLP-1-stimulated $\beta$ cell proliferation. Increased apoptosis was observed in TCF7L2-silenced islets. Overexpression of TCF $7 \mathrm{~L} 2$ protects islets from cytokine-induced cell apoptosis ${ }^{(66)}$

\section{Risk T-allele of rs7903146 and T2DM}

It was found that individuals carrying the risk T-allele had reduced basal and glucose-stimulated insulin secretion, elevated plasma proinsulin level and an increased proinsulin-to-insulin ratio (suggesting the possibility of affected proinsulin processing), and impaired incretin-potentiated insulin secretion ${ }^{(67)}$. Increased apoptosis was observed in individuals carrying the T-allele of rs7903146. The total mass of pancreatic tissue was not altered in pancreatic sections from CT/TTgenotype carriers compared with CCgenotype carriers. However, TT-genotype carriers had a lower number of islets and tended to have islets with larger diameters. Higher proportion of a -cells was also observed in the TT-genotype carriers, but not in CT-carriers compared to the CCcarriers ${ }^{(68)}$. Expression of TCF7L2 is increased in pancreatic islets from both healthy risk-allele carriers and T2DM patients ${ }^{(69)}$. In non-diabetic individuals, homozygous risk-genotype carriers (TT) have 2-2.6 fold higher expression of TCF7L2
mRNA in pancreatic islets compared to CC-genotype carriers, while diabetic homozygous TT-genotype carriers display a 5-fold increased TCF7L2 expression compared to CC-genotype carriers(70). Expression of TCF7L2 was elevated together with increase in $\beta$ cell mass during $\beta$ cell compensation phase, which decrease after the onset of the diabetes ${ }^{(63)}$. In islets from diabetic mice, the protein expression of TCF7L2 was reduced and mRNA expression was higher compared to the healthy controls ${ }^{(62)}$. The increase in TCF7L2 expression indicates that the increase of TCF7L2 expression might be a consequence, rather than a cause of defective insulin secretion ${ }^{(68)}$. Or, mRNA levels elevation may represent increased levels of transcripts encoding less active isoforms, or a transcript of TCF7L2 with inhibitory effect on insulin secretion, since there is alternative splicing in TCF7L2 that leads to multiple transcripts $(71)$.

\section{TCFL2 and hepatic glucose metabolism}

The TCF7L2 expression in the liver has major effects on metabolism. The $\mathrm{Wnt} / \mathrm{\beta}$-cat pathway is a major determinant of the hepatocyte metabolism. Food intake and insulin stimulate the expression of TCF7L2 in mouse hepatocytes(5). Wnt activation by lithium reduces gluconeogenesis. TCF7L2 seems to regulate expression of rate-limiting gluconeogenic enzymes, such as phosphorenol-pyruvate-carboxykinase and glucose-6-phosphatase. Silencing of TCF7L2 leads to increased basal glucose production in cultured hepatocytes, as well as impaired insulin suppressed glucose production(5) (Figure 3). This might explain the impaired hepatic insulin sensitivity observed in risk the T-allele of rs7903146(72). 


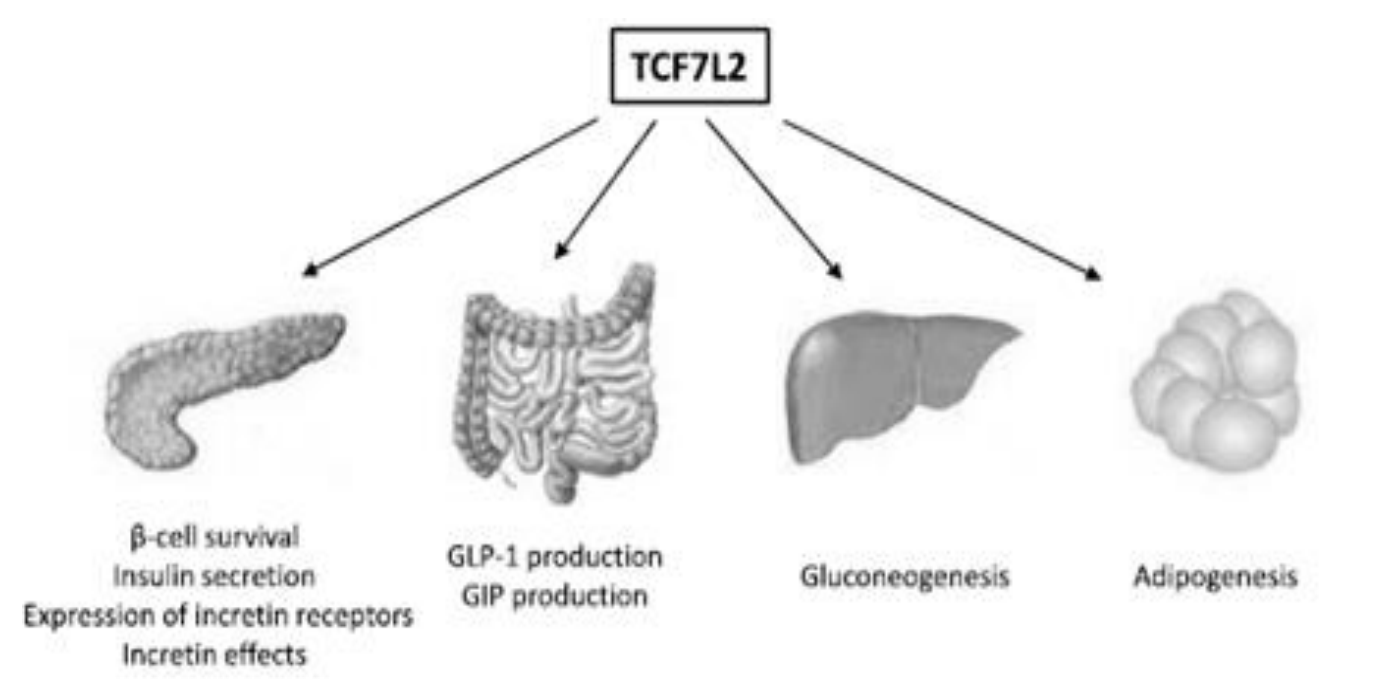

Figure 3: Summary of the potential metabolic functions of TCF7L2. GLP-1, glucagon-like peptide-1. GIP, gastric inhibitory polypeptide ${ }^{(73)}$

Effect of Wnt signaling on BMI

Wnt signaling plays a fundamental role in regulating adipogenesis and adipose cell differentiation(74), Unless Wnt signaling is inhibited, committed preadipocytes will not differentiate into mature adipose cells. In contrast, loss of function in the Wnt signaling cascade leads to rapid recruitment and growth of preadipocytes(75). It was described an apparent mutation of a Wnt protein (Wnt10B) in a family characterized by severe obesity, further linking this pathway to metabolic disorders. Thus, potentially increased Wnt signaling in carriers of the TCF7L2 risk variants could be expected to influence adipose tissue growth and development and, thus, $\mathrm{BMI}^{(74)}$.

Association of rs7903146 of TCF7L2 gene with secondary complications of T2DM

Wnt signaling works via disheveled receptors and transcription factors like $\beta$ catenin and TCF7L2, to modulate the expression of downstream target genes like IL1 (interleukin 1), TNF-a (tumor necrosis factor a), FGF (fibroblast growth factor), KGF (keratinocyte growth factor) and VEGF (vascular endothelial growth factor) ${ }^{(73)}$. This TCF7L2 gene polymorphism was found to be involved in sec- ondary complications of diabetes like nephropathy, neuropathy, retinopathy and cardiovascular disease ${ }^{(76)}$.

\section{Conclusion}

The association between TCF7L2 gene with T2DM have been confirmed. This review summarized several mechanisms of T2DM pathogenesis associated with TCF7L2, including genetic mutations, Wnt signaling pathway and function. A proper understanding of the mechanism will help the development of potential new therapeutics for T2DM.

\section{References}

1. Goyal R, Jialal I. Diabetes Mellitus Type 2: StatPearls Publishing, Treasure Island (FL); 2019.

2. Cersosimo E, Triplitt C, Solis-Herrera C, Mandarino L, DeFronzo R. Pathogenesis of type 2 diabetes mellitus.: Inc; 2018.

3. Mambiya $M$, Shang $M$, Wang $Y$, Li Q, Liu S, Yang L, et al. The Play of Genes and Non-genetic Factors on Type 2 Diabetes. Front Public Health. 2019;7:349-.

4. Musavi Z, Azarpira N, Sangtarash MH, Kordi M, Kazemi K, Geramizadeh B, et 
al. Polymorphism of Transcription Factor-7-Like 2 (TCF7L2) Gene and New-Onset Diabetes after Liver Transplantation. Int J Organ Transplant Med. 2015;6(1):14-22.

5. Jin T. Current understanding on role of the Wnt signaling pathway effector TCF7L2 in glucose homeostasis. Endocr Rev. 2016;37(3):254-77.

6. Abd El Razek NY, Wissa NR, Nassar $\mathrm{HM}$, Omar SA. Association of RS $7903146 \quad(C / T)$ Single Nucleotide Polymorphism at Transcription Factor 7 Like 2 Gene with Type 2 Diabetes Mellitus in Egyptian Patients. SCUMJ. 2016;19(1):29-38.

7. Jainandunsing $S$, Koole HR, van Miert JNI, Rietveld T, Wattimena JLD, Sijbrands EJG, et al. Transcription factor 7 -like 2 gene links increased in vivo insulin synthesis to type 2 diabetes. EBioMedicine. 2018;30:295302.

8. Groves CJ, Zeggini E, Minton J, Frayling TM, Weedon MN, Rayner NW, et al. Association analysis of 6,736 UK subjects provides replication and confirms TCF7L2 as a type 2 diabetes susceptibility gene with a substantial effect on individual risk. Diabetes Care. 2006;55(9):2640-4.

9. Scott LJ, Bonnycastle LL, Willer CJ, Sprau AG, Jackson AU, Narisu N, et al. Association of transcription factor 7like 2 (TCF7L2) variants with type 2 diabetes in a Finnish sample. Diabetes Care. 2006;55(9):2649-53.

10. Mayans S, Lackovic K, Lindgren $P$, Ruikka $\mathrm{K}$, Ågren $\AA$, Eliasson $\mathrm{M}$, et al. TCF7L2 polymorphisms are associated with type 2 diabetes in northern Sweden. Eur J Hum. 2007;15(3):342-6.

11. Gupta V, Khadgawat R, Ng HKT, Kumar S, Aggarwal A, Rao VR, et al. A validation study of type 2 diabetesrelated variants of the TCF7L2, HHEX, KCNJ11, and ADIPOQ genes in one endogamous ethnic group of North India. Ann Hum Genet. 2010;74(4):3618.

12. Wen J, Rönn T, Olsson A, Yang Z, Lu B,
Du $Y$, et al. Investigation of type 2 diabetes risk alleles support CDKN2A/B, CDKAL1, and TCF7L2 as susceptibility genes in a Han Chinese cohort. PloS one. 2010;5(2):e9153.

13. Palizban A, Nikpour $M$, Salehi R, Maracy M-R. Association of a common variant in TCF7L2 gene with type 2 diabetes mellitus in a Persian population. Clin Exp Med. 2012; 12(2): 115-9.

14. Cauchi S, El Achhab Y, Choquet H, Dina $C$, Krempler $F$, Weitgasser $R$, et al. TCF7L2 is reproducibly associated with type 2 diabetes in various ethnic groups: a global meta-analysis. J Mol Med. 2007;85(7):777-82.

15. Rees SD, Bellary S, Britten AC, O'Hare JP, Kumar S, Barnett $A H$, et al. Common variants of the TCF7L2gene are associated with increased risk of type 2 diabetes mellitus in a UKresident South Asian population. BMC Med Genet. 2008;9(1):8.

16. Ezzidi I, Mtiraoui N, Cauchi S, Vaillant $E$, Dechaume A, Chaieb $M$, et al. Contribution of type 2 diabetes associated loci in the Arabic population from Tunisia: a casecontrol study. BMC Med Genet. 2009;10(1):33.

17. Ereqat S, Nasereddin A, Cauchi S, Azmi $\mathrm{K}$, Abdeen Z, Amin R. Association of a common variant in TCF7L2 gene with type 2 diabetes mellitus in the Palestinian population. ACTA DIABETOL. 2010;47(1):195-8.

18. Saadi H, Nagelkerke N, Carruthers SG, Benedict S, Abdulkhalek S, Reed R, et al. Association of TCF7L2 polymorphism with diabetes mellitus, metabolic syndrome, and markers of beta cell function and insulin resistance in a population-based sample of Emirati subjects. Diabetes research clinical practice. 2008;80(3): 392-8.

19. Alsmadi O, Al-Rubeaan K, Mohamed G, Alkayal F, Al-Saud H, Al-Saud NA, et al. Weak or no association of TCF7L2 variants with Type 2 diabetes risk in an 
Arab population. BMC Med Genet. 2008;9(1):72.

20. Bahaaeldin AM, Seif AA, Hamed AI, Kabiel WAY. Transcription Factor 7Like-2 (TCF7L2) rs7903146 (C/T) Polymorphism in Patients with Type 2 Diabetes Mellitus. Dubai Diabetes Endocrinol J.1-7.

21. Buse JB, Wexler DJ, Tsapas A, Rossing $P$, Mingrone $G$, Mathieu $C$, et al. 2019 update to: management of hyperglycemia in type 2 diabetes, 2018. A consensus report by the American Diabetes Association (ADA) and the European Association for the Study of Diabetes (EASD). Diabetes Care. 2020;43(2):487-93.

22. Saeedi $P$, Salpea $P$, Karuranga $S$, Petersohn I, Malanda B, Gregg EW, et al. Mortality attributable to diabetes in 20-79 years old adults, 2019 estimates: Results from the International Diabetes Federation Diabetes Atlas. Diabetes Res Clin Pr. 2020:108086.

23. American Diabetes A. Diagnosis and classification of diabetes mellitus. Diabetes care. 2013;36 Suppl 1(Suppl 1):S67-S74.

24. Chawla A, Chawla R, Jaggi S. Microvasular and macrovascular complications in diabetes mellitus: Distinct or continuum? Indian J Endocrinol Metab. 2016;20(4):546-51.

25. Association A. 2. Classification and diagnosis of diabetes: standards of medical care in diabetes-2018. Diabetes Care. 2018;41 (Suppl 1): S13s27.

26. Baynes HW. Classification, pathophysiology, diagnosis and management of diabetes mellitus. J diabetes metab. 2015;6(5):1-9.

27. Williams VF, Oh G-T, Stahlman S, Shell D. Diabetes mellitus and gestational diabetes, active and reserve component service members and dependents, 2008-2018. MSMR. 2020; 27 (2):8-17.

28. Alam SS, Riaz S. Thiamine and the Cellular Energy Cycles-A Novel
Perspective on Type 2 Diabetes Treatment. Treatment of Type 2 Diabetes: IntechOpen; 2015.

29. Rich SS. Still a geneticist's nightmare. Nat Genet. 2016;536(7614):37-8.

30. Prasad RB, Groop L. Genetics of type 2 diabetes-pitfalls and possibilities. Genes (Basel). 2015;6(1):87-123.

31. Xue $A$, Wu $Y$, Zhu Z, Zhang F, Kemper $K E$, Zheng $Z$, et al. Genome-wide association analyses identify 143 risk variants and putative regulatory mechanisms for type 2 diabetes. Nat Commun. 2018;9(1):1-14.

32. Lawlor N, Khetan S, Ucar D, Stitzel ML. Genomics of Islet (Dys)function and Type 2 Diabetes. Trends Genet. 2017;33(4):244-55.

33. Park E, Pan Z, Zhang Z, Lin L, Xing Y. The Expanding Landscape of Alternative Splicing Variation in Human Populations. Am J Hum Genet. 2018;102(1):11-26.

34. Hasstedt SJ, Highland HM, Elbein SC, Hanis CL, Das SK, American Diabetes Association GSG. Five linkage regions each harbor multiple type 2 diabetes genes in the African American subset of the GENNID Study. J Hum Genet. 2013;58(6):378-83.

35. Rizvi S, Raza ST, Rahman Q, Mahdi F. Role of GNB3, NET, KCNJ11, TCF7L2 and $G R L$ genes single nucleotide polymorphism in the risk prediction of type 2 diabetes mellitus. 3 Biotech. 2016;6(2):255.

36. van de Wetering $M$, Oosterwegel $M$, Dooijes D, Clevers $H$. Identification and cloning of TCF-1, a T lymphocytespecific transcription factor containing a sequence-specific HMG box. EMBO J. 1991;10(1):123-32.

37. Sierra RA, Hoverter NP, Ramirez RN, Vuong LM, Mortazavi A, Merrill BJ, et al. TCF7L1 suppresses primitive streak gene expression to support human embryonic stem cell pluripotency. Development. 2018;145(4):dev161075.

38. Hrckulak D, Kolar M, Strnad H, Korinek V. TCF/LEF Transcription Factors: An Update from the Internet Resources. 
Cancers (Basel). 2016;8(7):70.

39. Ganmore I, Livny A, Ravona-Springer R, Cooper I, Alkelai A, Shelly S, et al. TCF7L2 polymorphisms are associated with amygdalar volume in elderly individuals with Type 2 Diabetes. Sci Rep. 2019;9(1):1-10.

40. Vural $\mathrm{H}$. Tcf7l2 gene polymorphism in $\mathrm{T} 2 \mathrm{dm}$ with patients in Turkish population. Clin Epigenetics. 2017; 3(3): 27.

41. Jin T. Current Knowledge on the Role of Wnt Signaling Pathway in Glucose Homeostasis. Molecular Nutrition and Diabetes: Elsevier; 2016. p. 357-69.

42. Jin TJEr. Current understanding on role of the Wnt signaling pathway effector TCF7L2 in glucose homeostasis. 2016;37(3):254-77.

43. Grant SF, Thorleifsson G, Reynisdottir I, Benediktsson R, Manolescu A, Sainz $J$, et al. Variant of transcription factor 7-like 2 (TCF7L2) gene confers risk of type 2 diabetes. Nat Genet. 2006;38(3):320-3.

44. Ding W, Xu L, Zhang L, Han Z, Jiang Q, Wang $Z$, et al. Meta-analysis of association between TCF7L2 polymorphism rs7903146 and type 2 diabetes mellitus. BMC Med Genet. 2018;19(1):38.

45. Wang J, Zhang J, Li L, Wang Y, Wang Q, Zhai $\mathrm{Y}$, et al. Association of rs12255372 in the TCF7L2 gene with type 2 diabetes mellitus: a metaanalysis. Braz J Med Biol Res. 2013;46(4):382-93.

46. Peng S, Zhu Y, Lü B, Xu F, Li X, Lai M. TCF7L2 gene polymorphisms and type 2 diabetes risk: a comprehensive and updated meta-analysis involving 121 174 subjects. Mutagenesis. 2013;28(1): 25-37.

47. Perugorria MJ, Olaizola P, Labiano I, Esparza-Baquer A, Marzioni M, Marin $J$, et al. Wnt- $\beta$-catenin signalling in liver development, health and disease. Nat Rev Gastroenterol Hepatol. 2019;16(2):121-36.

48. Bejsovec A. Wingless/Wnt signaling in Drosophila: the pattern and the pathway. Mol Reprod Dev. 2013;80 (11):882-94.

49. Zhan T, Rindtorff N, Boutros M. Wnt signaling in cancer. Oncogene. 2017;36(11):1461-73.

50. Gao C, Xiao G, Hu J. Regulation of Wnt/B-catenin signaling by posttranslational modifications. Cell Biosci. 2014;4(1):13-.

51. Mohammed MK, Shao C, Wang J, Wei Q, Wang $X$, Collier $Z$, et al. Wnt/ $\beta$ catenin signaling plays an everexpanding role in stem cell selfrenewal, tumorigenesis and cancer chemoresistance. Genes Dis. 2016;3(1):11-40.

52. MacDonald BT, He X. Frizzled and LRP5/6 receptors for $W n t / \beta$-catenin signaling. Cold Spring Harb Perspect Biol. 2012;4(12):a007880.

53. van Kappel EC, Maurice MM. Molecular regulation and pharmacological targeting of the $\beta$-catenin destruction complex. $\mathrm{Br} J$ Pharmacol. 2017;174(24):4575-88.

54. Schaefer KN, Peifer M. Wnt/BetaCatenin Signaling Regulation and a Role for Biomolecular Condensates. Dev Cell. 2019;48(4):429-44.

55. Beurel E, Grieco SF, Jope RS. Glycogen synthase kinase-3 (GSK3): regulation, actions, and diseases. Pharmacol Ther. 2015;148:114-31.

56. Wang $H$, Ren $Y$, Hu X, Ma M, Wang X, Liang $H$, et al. Effect of Wnt Signaling on the Differentiation of Islet $\beta$-Cells from Adipose-Derived Stem Cells. Biomed Res Int. 2017;2017:2501578-.

57. Cici D, Corrado A, Rotondo C, Cantatore FP. Wnt signaling and biological therapy in rheumatoid arthritis and spondyloarthritis. Int J Mol Sci. 2019;20(22):5552.

58. Pais R, Gribble FM, Reimann F. Stimulation of incretin secreting cells. Ther Adv Endocrinol Metab. 2016;7(1): 24-42.

59. Chiang Y-TA, Ip W, Jin T. The role of the Wnt signaling pathway in incretin hormone production and function. Front Physiol. 2012;3:273-. 
60. Shao W, Wang D, Chiang Y-T, Ip W, Zhu L, Xu F, et al. The Wnt signaling pathway effector TCF7L2 controls gut and brain proglucagon gene expression and glucose homeostasis. Diabetes. 2013;62(3):789-800.

61. Müller TD, Finan B, Bloom SR, D'Alessio D, Drucker DJ, Flatt PR, et al. Glucagon-like peptide 1 (GLP-1). Mol Metab. 2019;30:72-130.

62. Zhou Y, Park S-Y, Su J, Bailey K, Ottosson-Laakso E, Shcherbina L, et al. TCF7L2 is a master regulator of insulin production and processing. Hum Mol Genet. 2014;23(24):6419-31.

63. Mitchell RK, Mondragon A, Chen L, McGinty JA, French PM, Ferrer J, et al. Selective disruption of $\mathrm{Tcf} / 2$ in the pancreatic $\beta$ cell impairs secretory function and lowers $\beta$ cell mass. Hum Mol Genet. 2015;24(5):1390-9.

64. Yang H, Li Q, Lee J-H, Shu Y. Reduction in Tcf7l2 Expression Decreases Diabetic Susceptibility in Mice. Int J Biol Sci. 2012;8(6):791-801.

65. da Silva Xavier $G$, Mondragon A, Sun $G$, Chen L, McGinty J, French P, et al. Abnormal glucose tolerance and insulin secretion in pancreas-specific Tcf7l2-null mice. Diabetologia. 2012;55 (10):2667-76.

66. Yao DD, Yang L, Wang Y, Liu C, Wei YJ, Jia $X B$, et al. Geniposide promotes beta-cell regeneration and survival through regulating $\beta$-catenin/TCF7L2 pathway. Cell Death Dis. 2015;6 (5): e1746-e.

67. Ferreira $M C$, da Silva MER, Fukui RT, do Carmo Arruda-Marques M, Azhar S, dos Santos RF. Effect of TCF7L2 polymorphism on pancreatic hormones after exenatide in type 2 diabetes. Metab Syndr Relat Disord. 2019;11(1):10.

68. Ferreira $M C$, da Silva MER, Fukui RT, do Carmo Arruda-Marques $M$, dos Santos RF. TCF7L2 correlation in both insulin secretion and postprandial insulin sensitivity. Metab Syndr Relat Disord. 2018;10(1):37.
70. Adams JD, Vella A. What Can DiabetesAssociated Genetic Variation in TCF7L2 Teach Us About the Pathogenesis of Type 2 Diabetes? Metab Syndr Relat Disord. 2018;16(8):383-9.

71. Lyssenko V, Lupi R, Marchetti P, Del Guerra S, Orho-Melander M, Almgren $P$, et al. Mechanisms by which common variants in the TCF7L2 gene increase risk of type 2 diabetes. J Clin Invest. 2007;117(8):2155-63.

72. Pradas-Juni M, Nicod N, FernándezRebollo E, Gomis R. Differential transcriptional and posttranslational transcription factor 7-like regulation among nondiabetic individuals and type 2 diabetic patients. Mol Endocrinol. 2014;28(9):1558-70.

73. Cropano C, Santoro N, Groop L, Dalla Man C, Cobelli C, Galderisi A, et al. The rs7903146 Variant in the TCF7L2 Gene Increases the Risk of Prediabetes/Type 2 Diabetes in Obese Adolescents by Impairing $\beta$-Cell Function and Hepatic Insulin Sensitivity. Diabetes care. 2017;40(8):1082-9.

74. Ip W, Chiang Y-tA, Jin T, bioscience. The involvement of the wnt signaling pathway and TCF7L2 in diabetes mellitus: The current understanding, dispute, and perspective. Cell J. 2012;2(1):28.

75. Chen N, Wang J. Wnt/ß-Catenin Signaling and Obesity. Front Physiol. 2018;9:792-.

76. Bagchi DP, Nishii A, Li Z, DelProposto $J B$, Corsa CA, Mori $H$, et al. Wnt/Bcatenin signaling regulates adipose tissue lipogenesis and adipocytespecific loss is rigorously defended by neighboring stromal-vascular cells. Mol Metab. 2020;42:101078.

77. Ciccacci C, Di Fusco D, Cacciotti L, Morganti R, D'Amato C, Novelli G, et al. TCF7L2 gene polymorphisms and type 2 diabetes: association with diabetic retinopathy and cardiovascular autonomic neuropathy. Acta Diabetol. 2013;50(5):789-99. 